\title{
The Relationship of Alcohol and Other Drug Use Typologies to Sex Risk Behaviors among Vulnerable Women in Cape Town, South Africa
}

\section{Wendee M Wechsberg ${ }^{1,2,3,4 *}$, Bronwyn Myers ${ }^{5,6}$, Tracy L Kline ${ }^{7}$, Tara Carney ${ }^{8}$, Felicia A Browne ${ }^{9}$ and Scott P Novak $^{10}$}

${ }^{1}$ Senior Director, Substance Abuse Treatment and Interventions Research, RTI International, 3040 Cornwallis Road, Research Triangle Park, NC, USA

${ }^{2}$ Adjunct Professor, Health Policy and Administration, Gillings School of Global Public Health, The University of North Carolina, Chapel Hill, NC, USA

${ }^{3}$ Adjunct Professor, Psychology in the Public Interest, North Carolina State University (NCSU), Raleigh, NC, USA

${ }^{4}$ Adjunct Associate Professor, Psychiatry and Behavioral Sciences, Duke University School of Medicine, Durham, NC, USA

${ }^{5}$ Chief Specialist Scientist, Alcohol and Drug Abuse Research Unit, South African Medical Research Council, Francie Van Zijl Drive, Parow, South Africa

${ }^{6}$ Associate Professor, Department of Psychiatry and Mental Health, University of Cape Town, Anzio road Cape Town, South Africa

${ }^{7}$ Research Psychometrician, Statistics and Epidemiology, RTI International, 3040 Cornwallis Road, Research Triangle Park, North Carolina, USA

${ }^{8}$ Senior Scientist, Alcohol and Drug Abuse Research Unit, South African Medical Research Council, Francie Van Zijl Drive, Parow, South Africa

${ }^{9}$ Doctoral Student, Harvard School of Public Health, Harvard University, 677 Huntington Ave., Boston, MA, USA

${ }^{10}$ Senior Research Scientist Behavioral Health Epidemiology, RTI International, 3040 Cornwallis Road, Research Triangle Park, North Carolina, USA

\begin{abstract}
Background: Alcohol and other drug (AOD) use remains an important contributing factor to the spread of HIV in South Africa, mainly because of the strong associations found between AOD use and sex risk behaviors. Specifically, AOD use can lead to disinhibition and impaired judgment that may result in inconsistent condom use and other risky sex behaviors among vulnerable and disempowered women.
\end{abstract}

Methods: Latent Class Analysis was used to identify AOD use typologies among 720 vulnerable women from a randomized trial baseline assessment in Cape Town, South Africa and to examine whether these AOD use classes predict sex risk for HIV.

Results: Three classes emerged with distinct differences in AOD use: the Marijuana and Alcohol class (34.6\%) mainly comprised participants who used marijuana and drank alcohol frequently; the High AOD Risk class $(26.1 \%)$ mainly comprised participants who used methamphetamine and marijuana, reported heavy drinking, and moderate probabilities of Mandrax use; and the Polydrug use class (39.3\%) predominately comprised participants who used methamphetamine, marijuana, and Mandrax. Participants in the Marijuana and Alcohol class were less likely to report past-month unprotected sex with their main sex partner compared with participants in the Polydrug Use class. When examining the adjusted model, Black African women were significantly less likely to report past-month unprotected sex with their main sex partner compared with Coloured women. Women who were HIV negative were more likely to report unprotected sex with their main sex partner than women who were HIV positive.

Conclusion: The fewer substances that women used seemed to serve as protective factors against engaging in AOD-impaired sex. This study provides an important contribution to understand the intersection of AOD use and sexual risk for HIV by measuring polydrug use among vulnerable women and its association with sexual risk taking.

Keywords: Alcohol and other drug use; Women; Sex risk; Latent class analysis; South Africa

Abbreviations: AOD: Alcohol and Other Drugs; HIV: Human Immunodeficiency Virus; LCA: Latent Class Analysis; MSP: Main Sex Partner; RRBA: Revised Risk Behavior Assessment; STI: Sexually Transmitted Infection

\section{Introduction}

HIV infection poses one of the greatest threats to the well-being of South African women, with an estimated $13.6 \%$ of women aged between 15 and 49 being HIV positive in 2008 compared with $7.9 \%$ of men [1].While HIV prevalence in the Western Cape Province is significantly lower than the national estimate, the Western Cape is one of the few provinces where HIV prevalence is increasing [2]. Although South Africa has a generalized HIV epidemic that is mainly heterosexually transmitted, alcohol and other drug (AOD) use remains an important contributing factor to the spread of HIV in the country, mainly because of the strong associations found between AOD use and sex risk behaviors [3]. Specifically, AOD use leads to disinhibition and impaired judgment that may result in inconsistent condom use and other risky sex behaviors [3-5]. In addition, vulnerable women may engage in unsafe sex practices, such as trading sex in exchange for
AODs or money to buy AODs, or they may use AODs to cope with sex trading [6-7], which also holds multiple risks for exposure to HIV [7-8]. Alternatively, they may be disempowered in relationships to negotiate condom use, partly due to traditional gender roles where men are dominant and women are expected to be submissive to their partners in all matters, including sex [9].

This association between AOD use and HIV risk is disquieting given the high prevalence of AOD use in the country and particularly in the Western Cape province where the lifetime prevalence for any AOD

*Corresponding author: Wendee M Wechsberg, Senior Director, Substance Abuse Treatment, Evaluations \& Interventions Research, RTI International 3040 Cornwallis Road, USA, Tel: 919.541.6422; Fax: 919-485-5555; E-mail: wmw@rti.org

Received April 26, 2012; Accepted July 14, 2012; Published July 20, 2012

Citation: Wechsberg WM, Myers B, Kline TL, Carney T, Browne FA, et al. (2012) The Relationship of Alcohol and Other Drug Use Typologies to Sex Risk Behaviors among Vulnerable Women in Cape Town, South Africa. J AIDS Clinic Res S1:015. doi:10.4172/2155-6113.S1-015

Copyright: $\odot 2012$ Wechsberg WM, et al. This is an open-access article distributed under the terms of the Creative Commons Attribution License, which permits unrestricted use, distribution, and reproduction in any medium, provided the original author and source are credited. 
use disorder (defined by DSM-IV criteria for abuse or dependence) far exceeds the national average [10]. Given evidence of the high rates of AOD use in the region and the relationship between AOD use and HIV risk behaviors, adequate responses to decrease HIV incidence in the Western Cape should include interventions that target AODrelated sex risk behaviors among vulnerable women. In designing such interventions, it is important to consider how different patterns of $\mathrm{AOD}$ use are associated with variations in sex risk profiles. While there is a large body of research that has examined how alcohol or specific classes of drugs (such as methamphetamine) individually contribute to risky sex behaviors [3,9-14], there is less evidence for how the concurrent use of multiple substances affects HIV risk. This is of concern given evidence of high levels of multiple substance use among treatment and community samples of people who use drugs [15-17]. This trend is also apparent in the Western Cape, where $45 \%$ of all substance abuse treatment admissions are for multiple substance use [13]. Consequently, focusing on the sex risks associated with the use of individual drugs may lack real-world generalizability [16].

Some studies have shown that the concurrent use of multiple substances is associated with riskier sex practices [18-19] and greater risk for HIV infection [20] compared with the use of a single class of drug. However, all of these studies have been conducted in developedcountry settings among men who have sex with men. As such, it is unclear whether findings from these studies are generalizable to women from developing countries such as South Africa. In such settings there has been little prior research on how different patterns of AOD use relate to sex risk behaviors among women. This limited knowledge of how AOD use patterns impact on sex risk behaviors among women has restricted the extent to which sex risk reduction interventions can be designed to target different patterns and combinations of AOD use.

One effective way of examining AOD use typologies is through the use of Latent Class Analysis (LCA). This technique is used to reduce a large number of interrelated items into a smaller number of homogenous subtypes that share similar underlying characteristics. It has been widely used in developed countries to explore underlying patterns of drug use among cocaine and heroin users [21-22] and to understand how various types of risk profiles (e.g., high drug use, alcohol use without drug use, or no AOD use), or latent classes, differentially affect one's risk for infectious disease [16]. However, to the best of our knowledge, there have been no studies exploring how AOD use typologies relate to sex risk behaviors in a developing country such as South Africa.

This article aims to address this gap in the science by using LCA to identify AOD use typologies among vulnerable AOD-using women in Cape Town and to examine whether AOD use classes predict sex risk for HIV. If differences among the various classes of AOD use are found in relation to sex risk behavior, these findings could inform the development of targeted HIV risk-reduction interventions for vulnerable women in this setting.

\section{Materials and Methods}

\section{Study design and participants}

This article reports on baseline characteristics of the 720 women recruited into a randomized community-based trial to test an adapted evidence-based, behavioral HIV risk-reduction intervention (the Western Cape Women's Health CoOp) between September 2008 and January 2011. The details of this study are described elsewhere [23].

To be eligible for this study, participants had to be female, between
18 and 33 years old (which has the highest HIV prevalence among childbearing women), live in one of the study's target communities (which had high levels of socioeconomic disadvantage), used at least two types of drugs (one of which could be alcohol) at least once a week for the past 3 months, were sexually active with a male partner within the past month, and had not participated in previous Women's Health CoOp pilot or formative studies [24]. To ensure that recruitment was balanced across a range of disadvantaged township communities in the Cape Town area, community population estimates were used to calculate sampling targets for the 15 target communities.

\section{Data collection}

As the study target population is generally difficult to reach, trained peer-outreach workers used standard street-outreach techniques (such as marketing in areas frequented by the target population) to identify potential participants. Outreach staff approached potential participants and verbally requested permission to administer a brief screening instrument to determine whether they met study eligibility criteria. Women who met these criteria and were interested in the study were given an appointment for a baseline interview. At the appointment, women were rescreened and consented to participate in the study. Once enrolled, a peer interviewer administered the baseline questionnaire by using computer-assisted personal interviewing (CAPI) followed by biological testing for pregnancy, HIV, and the recent use of alcohol, cocaine, methamphetamine, marijuana, opiates, and Mandrax (methaqualone). Participants were provided with a grocery voucher valued at ZAR 40 (USD 5.71) for their time. Ethical approval for this study was granted by the Institutional Review Boards of RTI International and Stellenbosch University's Faculty of Health Sciences (Trial Registration Number: NCT00729391).

\section{Measures}

The CAPI baseline was a modified Revised Risk Behavior Assessment (RRBA) that was adapted for use in the Western Cape [25]. The RRBA collects self-report information from various domains pertaining to HIV risk, including demographics and social characteristics, health knowledge, alcohol use, drug use, injecting drug use, sex behaviors, power and empowerment, conflict and victimization, physical and mental health, and need for services. For this article, we report on the following variables.

Sociodemographic variables: The following sociodemographic variables were examined: age, ethnicity (Black African or Coloured [people of mixed-race ancestry who form a cultural grouping]); education status (whether or not they had completed 12th grade); current homelessness (yes/no); and current employment status (unemployed/employed).

Biological testing for the presence of HIV antibodies was conducted using two rapid finger prick tests. If participants tested positive for HIV antibodies on one or more test, a third confirmatory rapid test was conducted. Participants were considered HIV seropositive if at least two of these three tests were positive.

The number of sexually transmitted infection (STI) symptoms experienced in the 3 months preceding the study was explored using an adapted World Health Organization STI symptom checklist embedded in the RRBA [25]. This 12-item scale had a Cronbach alpha value of 0.93 .

Alcohol and other drug use: Self-report items on alcohol use explored the frequency and quantity of current alcohol consumption. 
Citation: Wechsberg WM, Myers B, Kline TL, Carney T, Browne FA, et al. (2012) The Relationship of Alcohol and Other Drug Use Typologies to Sex Risk Behaviors among Vulnerable Women in Cape Town, South Africa. J AIDS Clinic Res S1:015. doi:10.4172/2155-6113.S1-015

Page 3 of 8

"Frequent" drinking was defined as two or more drinking episodes per week and "heavy" drinking was defined as seven or more drinks per day. Current drug use was assessed through self-reported use of marijuana, methamphetamine, heroin, and Mandrax (methaqualone) during the month preceding the study.

Sex risk behavior: The main outcome variables of interest for this study were past month unprotected sex with main sex partner (MSP) (yes/no), past month unprotected sex with sex partners other than the main partner (yes/no), and AOD-impairment during last sex act (yes/ no). Here, AOD-impaired sex is defined as any AOD use just before or during sex. Other sex-risk behaviors included unprotected last sex act with any partner (yes/no), a participant's experience of the last sexual encounter (whether she was willing or not willing to have sex), whether a participant believes that her main partner's AOD use led to unprotected sex (yes/no), and whether a participant believes that her own AOD use led to unprotected sex (yes/no).

\section{Data analysis}

The overall goal was to use baseline data to characterize the association between AOD behaviors and risky sex. To examine the plausibility that distinct profiles of drug users exist in this population, Mplus statistical modeling software version 4.1 [26] was used to conduct LCA, a form of structural equation modeling [26]. LCA seeks to identify whether there are subgroups of individuals that share similar characteristics. Rather than analyzing each individual characteristic separately, this method parsimoniously categorizes a large number of characteristics into smaller subtypes. The value of this method is that these distinct profiles can then be used to understand whether there are differences in the profiles in response to intervention-relevant variables [26].

For this article, LCA was used to identify underlying profiles of AOD use based on similarities in patterns of past 30 day consumption. The following AOD use variables were used to define the subtypes: frequent drinking, heavy drinking, past month marijuana use, past month methamphetamine use, and past month use of Mandrax. These variables were selected because they exhibited sufficient variation and numbers of respondents endorsing each variable.

To determine the best number of latent groups, different classes were assessed using Akaike's Information Criterion (AIC) and Bayesian Information Criterion (BIC), where a reduction in numerical value indicates better fit. As there is no statistical test to determine the optimal number of classes, theoretical judgment was also used to distinguish between different options for classification (e.g., 3 class solution versus a 4 class solution) and equally fitting models. When sample size permits, a split-half approach is used to model validation that determines the final number of classes and assigns individual responses to a single class for later analyses. As the sample for this study did not permit the use of this method, classes were validated by varying the number of random starts in Mplus [26]. This procedure ensures that the local maxima are achieved under various initial starting points. Once the final latent class model was determined (using maximum likelihood estimation), each respondent was assigned to membership in a single latent class based on the probability of their highest class membership. Next, the classes were used as a categorical predictor variable for subsequent analyses.

To characterize the types of individuals in each class, chi-square tests were used to examine whether the identified classes differed from each other on the demographic and sex risk variables of interest. Thereafter, multivariate logistic regression procedures were performed to examine the impact of class membership and theoretically relevant demographics of age, ethnicity, unemployment status, education, and

\begin{tabular}{|c|c|c|c|}
\hline N Classes & Free Parameters & AIC & BIC \\
\hline 2 & 11 & 4168.272 & 4218.643 \\
\hline 3 & 17 & 4143.988 & 4221.836 \\
\hline 4 & 23 & 4120.104 & 4225.427 \\
\hline
\end{tabular}

Note: AIC: Akaike's Information Criterion; BIC: Bayesian Information Criterion Table 1: Latent Class Analysis Fit Statistics.

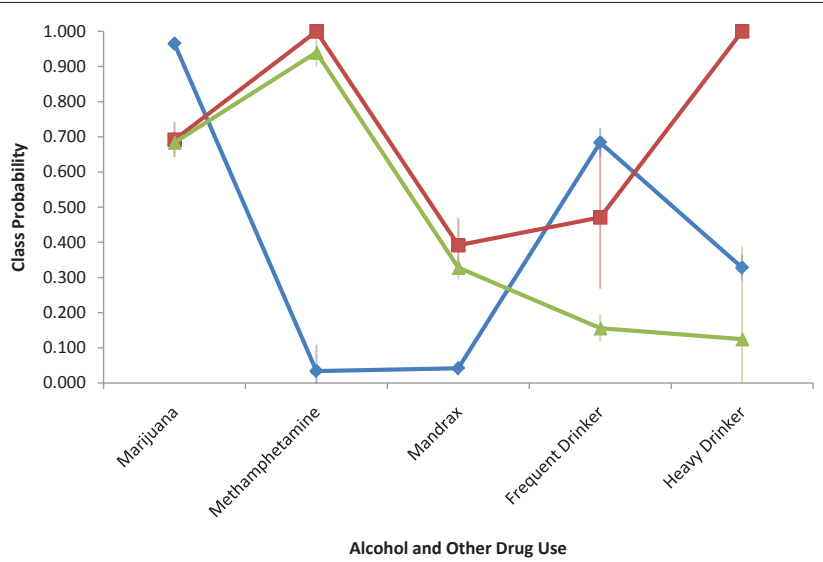

$\multimap$ Marijuana \& Alcohol $\rightarrow$ High AOD Risk $\quad \longrightarrow$ Polydrug Use

Figure 1: Probabilities of alcohol and other drug (AOD) use by class membership .

HIV status on significantly class-associated sexual risk behaviors.

\section{Results}

\section{Drug and alcohol use}

Marijuana was the most prevalent substance used by study participants. Overall, the prevalence of past month marijuana use was $78.0 \%$. The prevalence of past month methamphetamine use and Mandrax use was $64.0 \%$ and $24.0 \%$, respectively. For alcohol use, the prevalence of past month frequent drinking and past month heavy drinking was $40.0 \%$ and $37.5 \%$, respectively.

\section{Latent AOD class profiles}

Table 1 provides the fit statistics (AIC and BIC) for the 2, 3, and 4 class solutions. Based on these patterns of AOD use, a latent class model consisting of three classes was selected over the other class solutions, as the three-class solution had adequate reductions in the AIC and BIC indices while maintaining adequate class sizes of greater than 100 respondents. Once the final latent class model was determined (using maximum likelihood estimation), each respondent was assigned to membership in a single latent class based on the probability of their highest class membership (Class $1=0.35$, Class $2=0.26$, and Class $3=0.39$ ). Figure 1 shows the results of the LCA three-class solution, including the prevalence of AOD use indicators by class.

Classes are named based on the combination of substance use present in each class. Class 1 constitutes $34.6 \%(n=249)$ of the total sample and mainly comprised participants who used marijuana and drank alcohol frequently. As such, it is referred to as the "Marijuana and Alcohol" class. Class 2 constitutes $26.1 \%(n=188)$ of the sample and is predominantly comprised of participants with intense polydrug use, including high probabilities of methamphetamine use, heavy drinking, and marijuana use, and moderate probabilities of Mandrax use. This class is referred 
Citation: Wechsberg WM, Myers B, Kline TL, Carney T, Browne FA, et al. (2012) The Relationship of Alcohol and Other Drug Use Typologies to Sex Risk Behaviors among Vulnerable Women in Cape Town, South Africa. J AIDS Clinic Res S1:015. doi:10.4172/2155-6113.S1-015

Page 4 of 8

\begin{tabular}{|c|c|c|c|c|c|}
\hline Sociodemographic variable & $\begin{array}{c}\text { Class } 1 \\
\text { Marijuana and Alcohol } \\
N=249 \\
n(\%) \text { of Class }\end{array}$ & $\begin{array}{c}\text { Class } 2 \\
\text { High AOD Risk } \\
\mathrm{N}=188 \\
\mathrm{n}(\%) \text { of Class }\end{array}$ & $\begin{array}{c}\text { Class } 3 \\
\text { Polydrug Use } \\
\mathrm{N}=283 \\
\mathrm{n}(\%) \text { of Class }\end{array}$ & Chi-square (df) & $p$-value \\
\hline Age & & & & $2.54(2)$ & 0.28 \\
\hline $18-24$ & $173(69.5 \%)$ & $117(62.2 \%)$ & 189 (66.8\%) & & \\
\hline 25 and older & 76 (30.5\%) & $71(37.8 \%)$ & $94(33.2 \%)$ & & \\
\hline Ethnicity & & & & $241.21(2)$ & $<0.0001$ \\
\hline Black African & $210(84.3 \%)$ & $36(19.2 \%)$ & $78(27.6 \%)$ & & \\
\hline Coloured & $39(15.7 \%)$ & $152(80.9 \%)$ & $205(72.4 \%)$ & & \\
\hline Currently homeless & & & & $6.14(2)$ & 0.05 \\
\hline Yes & $1(0.4 \%)$ & $7(3.7 \%)$ & $7(2.5 \%)$ & & \\
\hline No & $248(99.6 \%)$ & $181(96.3 \%)$ & $276(97.5 \%)$ & & \\
\hline Unemployed & & & & $21.50(2)$ & $<0.0001$ \\
\hline Yes & $207(83.1 \%)$ & $180(95.7 \%)$ & 261 (92.2\%) & & \\
\hline No & $42(16.9 \%)$ & $8(4.3 \%)$ & $22(7.8 \%)$ & & \\
\hline Education & & & & $5.54(2)$ & 0.06 \\
\hline $11^{\text {th }}$ grade or less & $212(85.1 \%)$ & $172(91.5 \%)$ & $256(90.5 \%)$ & & \\
\hline $12^{\text {th }}$ grade or more & $37(14.9 \%)$ & $16(8.5 \%)$ & $27(9.5 \%)$ & & \\
\hline Biological HIV status $(\mathrm{N}=674)$ & & & & $28.92(2)$ & $<0.0001$ \\
\hline Negative & $159(68.2 \%)$ & $155(88.6 \%)$ & $221(83.1 \%)$ & & \\
\hline Positive & $74(31.8 \%)$ & $20(11.4 \%)$ & $45(16.9 \%)$ & & \\
\hline STI symptoms & & & & $28.71(4)$ & $<0.0001$ \\
\hline None & $141(56.6 \%)$ & $62(33.0 \%)$ & 147 (51.9\%) & & \\
\hline One to Two & $62(24.9 \%)$ & 66 (35.1\%) & 84 (29.7\%) & & \\
\hline Three or more & $46(18.5 \%)$ & $60(31.9 \%)$ & $52(18.4 \%)$ & & \\
\hline
\end{tabular}

Note: STI: Sexually Transmitted Infection

Table 2: Association cross-tabulation statistics between latent class membership and sociodemographic characteristics of women who use alcohol and other drugs in Cape Town, South Africa.

\begin{tabular}{|c|c|c|c|c|c|}
\hline Sex risk variable & $\begin{array}{c}\text { Marijuana and Alcohol } \\
\text { Class } 1 \\
\mathrm{~N}=249 \\
\mathrm{n}(\%) \text { of Class }\end{array}$ & $\begin{array}{c}\text { High AOD Risk } \\
\text { Class } 2 \\
N=188 \\
\text { n (\%) of Class }\end{array}$ & $\begin{array}{c}\text { Polydrug Use } \\
\text { Class } 3 \\
N=283 \\
n(\%) \text { of Class }\end{array}$ & Chi-square (df) & p-value \\
\hline Past month unprotected sex with main sex partner $(\mathrm{N}=688)$ & & & & $28.97(2)$ & $<0.0001$ \\
\hline Yes & $155(62.5 \%)$ & $142(80.7 \%)$ & $215(81.4 \%)$ & & \\
\hline No & $93(37.5 \%)$ & $34(19.3 \%)$ & $49(18.6 \%)$ & & \\
\hline Past month unprotected sex with other partners $(\mathrm{N}=159)$ & & & & $4.67(2)$ & 0.1 \\
\hline Yes & $9(25.0 \%)$ & $16(25.4 \%)$ & $25(41.7 \%)$ & & \\
\hline No & $27(75.0 \%)$ & $47(74.6 \%)$ & $35(58.3 \%)$ & & \\
\hline Unprotected last sex & & & & $32.45(2)$ & $<0.0001$ \\
\hline Yes & $140(56.2 \%)$ & $147(78.2 \%)$ & $214(75.6 \%)$ & & \\
\hline No & $109(43.8 \%)$ & $41(21.8 \%)$ & $69(24.4 \%)$ & & \\
\hline Experience at last sex & & & & $5.50(2)$ & 0.06 \\
\hline Not willing & $2(0.8 \%)$ & $8(4.3 \%)$ & $9(3.2 \%)$ & & \\
\hline Willing & $247(99.2 \%)$ & $180(95.7 \%)$ & $274(96.8 \%)$ & & \\
\hline AOD-impaired last sex & & & & $53.87(2)$ & $<0.0001$ \\
\hline Yes & $87(34.9 \%)$ & $130(69.2 \%)$ & $161(56.9 \%)$ & & \\
\hline No & $162(65.1 \%)$ & $58(30.9 \%)$ & $122(43.1 \%)$ & & \\
\hline Own AOD use leads to unprotected sex & & & & $19.05(2)$ & $<0.0001$ \\
\hline Yes & $40(16.1 \%)$ & $64(34.0 \%)$ & $68(24.0 \%)$ & & \\
\hline No & $209(83.9 \%)$ & $124(66.0 \%)$ & $215(76.0 \%)$ & & \\
\hline Main sex partner's AOD use leads to unprotected sex $(N=688)$ & & & & $24.59(2)$ & $<0.0001$ \\
\hline Yes & $31(12.5 \%)$ & $57(32.4 \%)$ & $62(23.5 \%)$ & & \\
\hline No & $217(87.5 \%)$ & $119(67.6 \%)$ & $202(76.5 \%)$ & & \\
\hline
\end{tabular}

Note: AOD: Alcohol and Other Drug; DF= Degrees of Freedom

Table 3: Association between latent class membership and sex risk behavior of women who use alcohol and other drugs in Cape Town, South Africa

to as the "High AOD Risk" class. Class 3 constitutes 39.3\% ( $\mathrm{n}=283)$ of the overall sample and has similar probabilities of methamphetamine, marijuana, and Mandrax use as Class 2, but low probabilities of heavy and frequent alcohol use. This class is referred to as the "Polydrug Use" class.

\section{Sociodemographic characteristics of AOD latent classes}

Table 2 presents sociodemographic characteristics associated with the three identified AOD use classes. Chi-square tests $\left(\chi^{2}(2), N=720\right.$ $=241.21 ; \mathrm{p}<0.0001)$ revealed significant differences in the ethnicity 
Citation: Wechsberg WM, Myers B, Kline TL, Carney T, Browne FA, et al. (2012) The Relationship of Alcohol and Other Drug Use Typologies to Sex Risk Behaviors among Vulnerable Women in Cape Town, South Africa. J AIDS Clinic Res S1:015. doi:10.4172/2155-6113.S1-015

Page 5 of 8

proportions across classes, with a higher proportion of Black African participants in the Marijuana and Alcohol class (Class 1, 84.3\%) than in the High AOD Risk class (Class 2, 19.2\%) or Polydrug Use class (Class 3, 27.6\%). Likewise, Coloured women were much more likely to be in the High AOD Risk and Polydrug Use classes (80.9\% and 72.4\%, respectively).

Homelessness status also differed across the classes $\left(\chi^{2}(2), \mathrm{N}=720=\right.$ 6.14; $\mathrm{p}=0.05)$, with a higher proportion of participants in the High AOD Risk class (3.7\%) reporting past month homelessness compared with participants in the Marijuana and Alcohol class $(0.4 \%)$ or the Polydrug Use class (2.5\%). Employment status also differed across the classes $\left(\chi^{2}(2), \mathrm{N}=\right.$ $720=21.50 ; p<0.0001)$; with the High AOD Risk class having the highest percentage of women reporting unemployment (95.7\%) compared with the Marijuana and Alcohol class (83.1\%) or Polydrug Use class (92.2\%). In addition, HIV status differed significantly across the classes $\left(\chi^{2}(2), \mathrm{N}=\right.$ $720=28.92 ; \mathrm{p}<0.0001)$, with the Marijuana and Alcohol use class having the highest proportion of HIV seropositive women (31.8\%) compared with the High AOD Risk class (11.4\%) or the Polydrug Use class (16.9\%). Finally, women in the High AOD Risk class had a greater percentage of participants reporting three or more STI symptoms (31.9\%) compared with women in the Marijuana and Alcohol class (18.5\%) or the Polydrug Use class $\left(18.4 ; \chi^{2}(4), \mathrm{N}=720=28.71 ; \mathrm{p}<0.0001\right)$.

\section{Sexual risk behaviors associated with AOD latent class profiles}

Table 3 depicts statistically significant differences in sex risk behaviors among the different classes of AOD use. Fewer women (62.5\%) in the Marijuana and Alcohol class reported past month unprotected sex with an MSP compared with women in the High AOD Risk class (80.7\%) or Polydrug Use class $\left(81.4 \% ; \chi^{2}(2), \mathrm{N}=688=28.97\right.$; $\mathrm{p}<0.0001)$. Similarly, a smaller proportion of women $(56.2 \%)$ in the Marijuana and Alcohol class reported unprotected last sex compared with women in the High AOD Risk class (78.2\%) or the Polydrug Use class $\left(75.6 \% ; \chi^{2}(2), \mathrm{N}=720=32.45 ; \mathrm{p}<0.0001\right)$. In contrast, more women in the High AOD Risk class (69.2\%) reported having AODimpaired last sex compared with women in the Polydrug Use class (56.9\%) or the Marijuana and Alcohol class (34.9\%; $\chi^{2}(2), \mathrm{N}=720=$ 53.87; $\mathrm{p}<0.0001)$. More women in the High AOD Risk class $(34.0 \%)$ reported that they believe their own AOD use leads to unprotected sex compared with women in the Marijuana and Alcohol class (16.1\%) or the Polydrug Use class $\left(24.0 \% ; \chi^{2}(2), N=720=19.05 ; \mathrm{p}<0.0001\right)$. Finally, more women in the High AOD Risk class (32.4\%) reported they believe that their MSP's AOD use leads to unprotected sex as compared with the Polydrug Use class (23.5\%) or the Marijuana and Alcohol class $\left(12.5 \% ; \chi^{2}(2), \mathrm{N}=688=24.59 ; \mathrm{p}<0.0001\right)$.

\begin{tabular}{|c|c|c|c|c|c|c|c|c|c|c|c|c|}
\hline & \multicolumn{4}{|c|}{ Unprotected Sex-MSP } & \multicolumn{4}{|c|}{ Impaired Last Sex } & \multicolumn{4}{|c|}{ Unprotected Last Sex } \\
\hline & \multicolumn{2}{|c|}{ Latent Class Only } & \multicolumn{2}{|c|}{$\begin{array}{l}\text { Class \& } \\
\text { Covariates }\end{array}$} & \multicolumn{2}{|c|}{ Latent Class Only } & \multicolumn{2}{|c|}{ Latent Class Only } & \multicolumn{2}{|c|}{ Latent Class Only } & \multicolumn{2}{|c|}{$\begin{array}{c}\text { Class \& } \\
\text { Covariates }\end{array}$} \\
\hline & $\begin{array}{c}\text { OR } \\
(95 \% \mathrm{Cl})\end{array}$ & Sig & $\begin{array}{c}\text { AOR } \\
(95 \% \mathrm{Cl})\end{array}$ & Sig & $\begin{array}{c}\text { OR } \\
(95 \% \mathrm{Cl})\end{array}$ & Sig & $\begin{array}{c}\text { AOR } \\
(95 \% \mathrm{Cl})\end{array}$ & Sig & OR $(95 \% \mathrm{Cl})$ & Sig & $\begin{array}{c}\text { AOR } \\
(95 \% \mathrm{Cl})\end{array}$ & Sig \\
\hline Latent Classes & & $<0.0001$ & & 0.07 & & $<0.0001$ & & 0.02 & & $<0.0001$ & & 0.25 \\
\hline $\begin{array}{l}\text { Marijuana and Alcohol vs. Polydrug } \\
\text { Use (ref) }\end{array}$ & $\begin{array}{c}0.38 \\
(0.25-0.57)\end{array}$ & $<0.0001$ & $\begin{array}{c}0.58 \\
(0.36-0.94)\end{array}$ & 0.03 & $\begin{array}{c}0.41 \\
(0.29-0.58)\end{array}$ & $<0.0001$ & $\begin{array}{c}0.76 \\
(0.49-1.17)\end{array}$ & 0.22 & $\begin{array}{c}0.41 \\
(0.29-0.60)\end{array}$ & $<0.0001$ & $\begin{array}{c}0.68 \\
(0.44-1.07)\end{array}$ & 0.1 \\
\hline High AOD Risk vs. Polydrug Use (ref) & $\begin{array}{c}0.95 \\
(0.59-1.55)\end{array}$ & 0.84 & $\begin{array}{c}0.69 \\
(0.41-1.15)\end{array}$ & 0.15 & $\begin{array}{c}1.70 \\
(1.15-2.51)\end{array}$ & 0.008 & $\begin{array}{c}1.52 \\
(1.01-2.29)\end{array}$ & 0.05 & $\begin{array}{c}1.16 \\
(0.75-1.80)\end{array}$ & 0.52 & $\begin{array}{c}0.90 \\
(0.56-1.43)\end{array}$ & 0.65 \\
\hline $\begin{array}{l}\text { High AOD Risk vs. Marijuana and } \\
\text { Alcohol (ref) }\end{array}$ & $\begin{array}{c}2.51 \\
(1.59-3.95)\end{array}$ & $<0.0001$ & $\begin{array}{c}1.19 \\
(0.68-2.07)\end{array}$ & 0.55 & $\begin{array}{c}4.17 \\
(2.78-6.25)\end{array}$ & $<0.0001$ & $\begin{array}{c}1.99 \\
(1.21-3.28)\end{array}$ & 0.006 & $\begin{array}{c}2.79 \\
(1.82-4.28)\end{array}$ & $<0.0001$ & $\begin{array}{c}1.31 \\
(0.78-2.22)\end{array}$ & 0.31 \\
\hline Age & & - & & 0.14 & & - & & 0.08 & & - & & 0.05 \\
\hline $18-24$ vs. $25+$ & - & & $\begin{array}{c}0.73 \\
(0.48-1.11)\end{array}$ & & - & & $\begin{array}{c}0.73 \\
(0.52-1.04)\end{array}$ & & - & & $\begin{array}{c}0.68 \\
(0.46-0.99)\end{array}$ & \\
\hline Ethnicity & & - & & 0.005 & & - & & $<0.0001$ & & - & & 0.001 \\
\hline Black African vs. Coloured (ref) & - & & $\begin{array}{c}0.49 \\
(0.30-0.81)\end{array}$ & & - & & $\begin{array}{c}0.33 \\
(0.21-0.50)\end{array}$ & & - & & $\begin{array}{c}0.46 \\
(0.29-0.72)\end{array}$ & \\
\hline Education & & - & & 0.61 & & - & & 0.64 & & - & & 0.56 \\
\hline Less than 11 th vs 12 th + & - & & $\begin{array}{c}1.16 \\
(0.66-2.06)\end{array}$ & & - & & $\begin{array}{c}1.14 \\
(0.67-1.94)\end{array}$ & & - & & $\begin{array}{c}1.18 \\
(0.68-2.02)\end{array}$ & \\
\hline HIV Status & & - & & 0.001 & & - & & 0.1 & & - & & 0.01 \\
\hline HIV- vs. HIV+ (ref) & - & & $\begin{array}{c}2.09 \\
(1.34-3.27)\end{array}$ & & - & & $\begin{array}{c}0.69 \\
(0.45-1.07)\end{array}$ & & - & & $\begin{array}{c}1.74 \\
(1.13-2.66)\end{array}$ & \\
\hline Unemployment & & - & & 0.28 & & - & & 0.54 & & - & & 0.91 \\
\hline Employed vs Unemployed & - & & $\begin{array}{c}0.72 \\
(0.39-1.32)\end{array}$ & & - & & $\begin{array}{c}0.84 \\
(0.48-1.47)\end{array}$ & & - & & $\begin{array}{c}0.97 \\
(0.55-1.72)\end{array}$ & \\
\hline
\end{tabular}

Note: OR: Odds Ratio; $\mathrm{Cl}$ : Confidence Interval

Table 4: Logistic regression analyses of alcohol and other drug use (AOD) latent classes on sex behavior outcomes. 
Citation: Wechsberg WM, Myers B, Kline TL, Carney T, Browne FA, et al. (2012) The Relationship of Alcohol and Other Drug Use Typologies to Sex Risk Behaviors among Vulnerable Women in Cape Town, South Africa. J AIDS Clinic Res S1:015. doi:10.4172/2155-6113.S1-015

Page 6 of 8

\begin{tabular}{|c|c|c|c|c|c|c|c|c|}
\hline & \multicolumn{4}{|c|}{ AOD to Unprotected Sex - Participant } & \multicolumn{4}{|c|}{ AOD to Unprotected Sex - MSP } \\
\hline & \multicolumn{2}{|c|}{ Latent Class Only } & \multicolumn{2}{|c|}{ Class \& Covariates } & \multicolumn{2}{|c|}{ Latent Class Only } & \multicolumn{2}{|c|}{ Class \& Covariates } \\
\hline & OR $(95 \% \mathrm{CI})$ & Sig & AOR (95\% Cl) & Sig & OR $(95 \% \mathrm{CI})$ & Sig & AOR $(95 \% \mathrm{Cl})$ & Sig \\
\hline Latent Classes & & $<0.0001$ & & 0.24 & & $<0.0001$ & & 0.34 \\
\hline Marijuana and Alcohol vs. Polydrug Use (ref) & $0.61(0.39-0.93)$ & 0.02 & $1.01(0.59-1.75)$ & 0.96 & $0.47(0.29-0.75)$ & 0.002 & $0.91(0.51-1.63)$ & 0.76 \\
\hline High AOD Risk vs. Polydrug Use (ref) & $1.63(1.09-2.45)$ & 0.02 & $1.42(0.93-2.18)$ & 0.11 & $1.56(1.02-2.39)$ & 0.04 & $1.34(0.85-2.11)$ & 0.2 \\
\hline High AOD Risk vs. Marijuana and Alcohol (ref) & $2.70(1.71-4.24)$ & $<0.0001$ & $1.40(0.79-2.50)$ & 0.25 & $3.35(2.05-5.48)$ & $<0.0001$ & $1.47(0.80-2.72)$ & 0.22 \\
\hline Age & & - & & 0.13 & & - & & 0.08 \\
\hline $18-24$ vs. $25+$ & - & & $0.75(0.51-1.09)$ & & - & & $0.70(0.47-1.05)$ & \\
\hline Ethnicity & & - & & 0.0003 & & - & & $<0.0001$ \\
\hline Black African vs. Coloured (ref) & - & & $0.37(0.22-0.64)$ & & - & & $0.31(0.18-0.55)$ & \\
\hline Education & & - & & 0.02 & & - & & 0.02 \\
\hline Less than 11 th vs 12 th + & - & & $2.77(1.21-6.35)$ & & - & & $2.78(1.14-6.81)$ & \\
\hline HIV Status & & - & & 0.87 & & - & & 0.94 \\
\hline HIV- vs. HIV+ (ref) & - & & $1.05(0.61-1.81)$ & & - & & $0.98(0.54-1.76)$ & \\
\hline Unemployment & & - & & 0.16 & & - & & 0.13 \\
\hline Employed vs Unemployed & - & & $0.58(0.27-1.24)$ & & - & & $0.50(0.20-1.22)$ & \\
\hline
\end{tabular}

Note: OR: Odds Ratio; AOR: Adjusted Odds Ratio; Cl: Confidence Interval

Table 4: (Continued) Logistic regression analyses of alcohol and other drug use (AOD) latent classes on sex behavior outcomes

\section{Adjusted associations between AOD latent classes and main sex risk outcomes}

Table 4 contains the results of the multivariate logistic regression analyses with sexual risk variables significantly associated with latent class membership. When examined alone, latent class membership was significantly associated with the likelihood of participants having unprotected sex with their MSP. Women in the Marijuana and Alcohol class had significantly smaller odds of having unprotected sex with their MSP than women in the Polydrug Use class $(\mathrm{OR}=0.38$; $95 \% \mathrm{CI}=0.25$ 0.57). Likewise women in the High AOD Risk class had significantly greater odds of having unprotected sex with their MSP than women in the Marijuana and Alcohol class $(\mathrm{OR}=2.51 ; 95 \% \mathrm{CI}=1.59-3.95)$. When the model was adjusted for the influences of age, ethnicity, education, HIV status, and unemployment, AOD latent class membership was no longer significantly associated overall with unprotected sex with MSP; however, women in the Marijuana and Alcohol class still had significantly reduced odds of reporting past month unprotected sex with their MSP compared with women in the Polydrug Use class (AOR $=0.58 ; 95 \% \mathrm{CI}=0.36-0.94)$. In this adjusted model, ethnicity ( $\mathrm{AOR}$ $=0.49 ; 95 \% \mathrm{CI}=0.30-0.81)$ and HIV status $(\mathrm{AOR}=2.09 ; 95 \% \mathrm{CI}=$ 1.34-3.27) were significantly associated with past month unprotected sex with MSP.

In an unadjusted model (Table 4), AOD latent class membership was significantly associated with AOD impairment at last sex, where women in the High AOD Risk class were significantly more likely to report AOD impairment at last sex than women in the Marijuana and Alcohol class $(\mathrm{OR}=4.17 ; 95 \% \mathrm{CI}=2.78-6.25)$ or the Polydrug Use class $(\mathrm{OR}=1.70$; $95 \% \mathrm{CI}=1.15-2.51$ ), respectively. Women in the Marijuana and Alcohol class also reported significantly smaller odds of AOD impairment at last sex compared with women in the Polydrug Use class $(\mathrm{OR}=0.41$; $95 \% \mathrm{CI}=0.29-0.58$ ). When the potential influences of confounders were adjusted for, AOD latent class membership remained significantly associated with AOD impairment at last sex, with women in the High AOD Risk class having greater odds of impairment compared with the Polydrug Use group (AOR $=1.52 ; 95 \% \mathrm{CI}=1.01-2.29)$ and nearly two times the odds of AOD impairment at last sex compared with women in the Marijuana and Alcohol class $(\mathrm{AOR}=1.99 ; 95 \% \mathrm{CI}=1.21-3.28)$.
Ethnicity ( $\mathrm{AOR}=0.33 ; 95 \% \mathrm{CI}=0.21-0.50)$ was significantly associated with AOD impairment at last sex in the adjusted model (Table 4). Black African women were less likely to report AOD impairment at last sex than Coloured women.

When examined alone, latent class membership was significantly associated with the likelihood of participants having unprotected sex during their last sex act, with women in the Marijuana and Alcohol class showing significantly smaller odds of having unprotected sex this last time than women in the Polydrug Use class (OR $=0.41 ; 95 \%$ $\mathrm{CI}=0.29-0.60)$. Similarly, women in the High AOD Risk class had significantly greater odds of having unprotected last sex than women in the Marijuana and Alcohol class $(\mathrm{OR}=2.79 ; 95 \% \mathrm{CI}=1.82-4.28)$. When potential confounders were added to the model, AOD latent class membership was no longer significantly associated with unprotected last sex. In this adjusted model, age group $(\mathrm{AOR}=0.68 ; 95 \% \mathrm{CI}=0.46$ $-0.99)$, ethnicity (AOR $=0.46 ; 95 \% \mathrm{CI}=0.29-0.72)$ and HIV status $(\mathrm{AOR}=1.74 ; 95 \% \mathrm{CI}=1.13-2.66)$ were significantly associated with unprotected last sex.

The belief that AOD use leads to unprotected sex, whether it was the participant's own or her MSP's AOD use, was significantly associated with AOD use class membership.Women in the High AOD Risk group had significantly greater odds of reporting a belief that their AOD use leads to unprotected sex than women in either the Polydrug Use class $(\mathrm{OR}=1.63 ; 95 \% \mathrm{CI}=1.09-2.45)$ or the Marijuana and Alcohol Class $(\mathrm{OR}=2.70 ; 95 \% \mathrm{CI}=1.71-4.24)$. This same class pattern was observed when women were thinking about their MSP's AOD use (Table 4). These relationships were no longer significant when significant demographic confounders of ethnicity (Participant AOD Use: AOR $=0.37 ; 95 \%$ CI $=0.22-0.64$, MSP's AOD Use: $\mathrm{AOR}=0.31 ; 95 \% \mathrm{CI}=0.18-0.55)$ and education (Participant AOD Use: $\mathrm{AOR}=2.77$; 95\% CI $=1.21-6.35$, MSP's AOD Use: AOR $=2.78 ; 95 \% \mathrm{CI}=1.14-6.81$ ) were controlled for in the analyses.

\section{Discussion}

Previous work on the association between polydrug use and sex risk behavior has been conducted almost entirely in high-income countries and among men who have sex with men [18-20]. This study is one of 
the first to use LCA to examine associations between polydrug use and sex risk for HIV among vulnerable women from a low- and middleincome country. Consequently, the findings from this study potentially help deepen current understanding of how AOD use typologies impact sex risk behaviors and may help to inform the design of interventions to reduce sex risk behaviors among vulnerable women. More specifically, the study has several important findings.

First, we identified three AOD use typologies among this sample of vulnerable women that differed according to the degree of polydrug use. Specifically, there was a high prevalence of problematic polydrug use, with more than a quarter of participants grouped into a High AOD Risk class and close to $40 \%$ of participants grouped into a Polydrug Use class. Women in both of these classes reported the use of multiple types of drugs, including methamphetamine and Mandrax (although only women in the High AOD Risk class had high probabilities of engaging in heavy episodic drinking). While the findings regarding heavy alcohol use among vulnerable women are consistent with those reported by earlier population surveys [11-12], our findings are among the first to show that intense polydrug use is relatively common among AODusing out-of-treatment women in Cape Town and highlight high levels of unmet treatment need. This is cause for concern because women from this region have limited access to and experience more barriers to accessing drug intervention services than men [27]. Our unexpectedly high rate of polydrug use highlights the need to improve access to drug risk reduction services for women in this region. Failure to improve access to drug treatment for women who use multiple substances not only represents a missed opportunity to intervene with their AOD use but also may have unintended adverse consequences for efforts to curtail the spread of HIV in the region [3,28].

Second, we found that these AOD use typologies predict sex risk for HIV; specifically women with high probabilities of multiple drug use were significantly more likely to engage in sex behaviors that place them at risk for HIV than women with less polydrug use. We found that using fewer substances appears to protect women from having unprotected sex with their MSP. Even after adjusting for the influence of potential confounders, women in the Marijuana and Alcohol class were significantly less likely to report past month unprotected sex with their MSP than participants the Polydrug Use class. Using fewer substances also seems to protect women from engaging in AOD-impaired sex. Even after adjusting for the influence of potential confounders, our findings show that women in the High AOD Risk class had greater odds of engaging in AOD-impaired sex than women in the Polydrug Use class and had almost double the odds of being AOD impaired at last sex than women in the Marijuana and Alcohol class. Together these findings suggest that a woman-focused drug risk reduction intervention that focuses on changing the number and types of drugs used may help reduce the extent to which vulnerable women engage in sex risk behaviors and could empower them to reduce their HIV risk.

Third, our findings show that sex risk behavior has a relationship with ethnicity. Even with associated covariates (such as education), Black African women were half as likely to engage in unprotected sex with their MSP and were two thirds less likely to report being AOD impaired at last sex act than Coloured women. One explanation for these findings may lie in the high prevalence of HIV among Black African communities relative to Coloured communities in the Western Cape [1,2]. Given these differences in HIV prevalence, Black African women may be more likely to know of people living with HIV and therefore more likely to view themselves as susceptible to HIV compared with Coloured women. This may influence the degree to which they take measures to protect themselves against HIV. This explanation is supported by prior studies conducted in this region that identified a negative relationship between HIV risk perception and engagement in sex risk behaviors for women [29]. Regardless of the reason, these findings clearly point to the need for interventions aimed at reducing sex risk behaviors for HIV among AOD-using Coloured women.

\section{Limitations}

The study findings should be considered in light of some limitations. One limitation is that the study used a narrow sampling frame: young AOD-using women from impoverished communities in Cape Town. Consequently, the findings may not be generalizable beyond the target of vulnerable women living in these communities. Another potential limitation is that these typologies were based on cross-sectional data and participants' risk profiles could vary over time. Therefore, repeated measurements should be collected to determine whether these typologies are stable. Further, the cross-sectional nature of these data makes it difficult to unpack the temporal associations between AOD use and HIV status; it is plausible that HIV status may also influence patterns of AOD use. Also, this study does not begin to explain why young women in these South African communities use AODs. Although previous studies have identified high unemployment and poverty, stress and boredom as reasons for AOD use [30], the reasons why young women begin and continue to use AODs requires further investigation.

\section{Conclusion}

Despite these limitations, this study provides an important contribution to understanding the intersection between AOD use and sex behaviors by identifying typologies of AOD use and its relationship to sex risk behaviors. To our knowledge, this study is the first to examine AOD use typologies among women in South Africa and whether they are associated with differences in sex risk behavior. We found that the relationship between AOD use and sexual risk for HIV varied by the type and combination of substances being used, with greater AOD use associated with heightened risk. Findings suggest that targeted women's interventions aimed at reducing polydrug use among vulnerable women are essential for reducing sex risks for HIV. Interventions in this region may need to include how gender roles and cultural expectations keep women from asserting sexual protection and how AOD use may also impede any risk reduction behaviors.

\section{Acknowledgements}

This research was supported by grant R01HD058320 (Wechsberg) from the Eunice Kennedy Shriver National Institute of Child Health and Human Development (NICHD). We wish to thank all of our project staff, the women participants, and our editor, Mr. Jeffrey Novey, for their contribution to this project.

\section{References}

1. Shisana O, Rehle T, Simbayi LC, Zuma K, Jooste S, et al. (2009) South African national HIV prevalence, incidence, behaviour and communication survey 2008: A turning tide among teenagers? Cape Town, HSRC Press, South Africa.

2. National Department of Health (2011) Report on National HIV and Syphilis Antenatal Sero-Prevalence Survey in South Africa 2010. National Department of Health. Pretoria, South Africa.

3. Parry C, Pithey A (2006) Risk behavior and HIV among drug using populations in South Africa. Afr J Drug Alcohol Stud 5: 139-156.

4. Kalichman SC, Simbayi LC, Cain D (2010) HIV transmission risk behaviors among HIV seropositive sexually transmitted infection clinic patients in Cape Town, South Africa. Eur J Public Health 20: 202-206.

5. Wechsberg WM, Jones HE, Zule WA, Myers BJ, Browne FA, et al. (2010) 
Citation: Wechsberg WM, Myers B, Kline TL, Carney T, Browne FA, et al. (2012) The Relationship of Alcohol and Other Drug Use Typologies to Sex Risk Behaviors among Vulnerable Women in Cape Town, South Africa. J AIDS Clinic Res S1:015. doi:10.4172/2155-6113.S1-015

Methamphetamine ("tik") use and its association with condom use among outof-school females in Cape Town, South Africa. Am J Drug Alcohol Abuse 36: 208-213

6. Parry CD, Dewing S, Petersen P, Carney T, Needle R, et al. (2009) Rapid assessment of HIV risk in drug using sex workers in three cities in South Africa. AIDS Behav 13: 849-859.

7. Wechsberg WM, Luseno WK, Lam WK, Parry CD, Morojele NK (2006) Substance use, sexual risk, and violence: HIV prevention intervention with sex workers in Pretoria. AIDS Behav 10: 131-137.

8. Dunkle KL, Jewkes RK, Brown HC, Gray GE, Mclntryre JA, et al. (2004) Transactional sex among women in Soweto, South Africa: prevalence, risk factors and association with HIV infection. Soc Sci Med 59: 1581-1592.

9. Wechsberg WM, Luseno W, Riehman K, Karg R, Browne F, et al. (2008) Substance use and sexual risk within the context of gender inequality in South Africa. Subst Use Misuse 43: 1186-1201.

10. Herman AA, Stein DJ, Seedat S, Heeringa SG, Moomal H, et al. (2009) The South African Stress and Health (SASH) study: 12-month and lifetime prevalence of common mental disorders. S Afr Med J 99: 339-344.

11. Peltzer K, Davids A, Njuho P (2011) Alcohol use and problem drinking in South Africa: Findings from a national population-based survey. Afr J Psychiatry (Johannesbg) 14: 30-37.

12. OrcMacro (2003) South Africa Demographic and Health Survey 2003. Nationa Department of Health, Medical Research Council, Department of Health, Pretoria, South Africa.

13. Dada S, Pluddemann A, Parry C, Bhana A, Vawda M, et al. (2011) Alcohol and drug abuse trends: January-June 2011 (Phase 30). South African Community Epidemiology Network on Drug Use (SACENDU). Cape Town, South Africa.

14. Rawson RA, Gonzales R, Pearce V, Ang A, Marinelli-Casey P, et al. (2008) Methamphetamine dependence and human immunodeficiency virus risk behavior. J Subst Abuse Treat 35: 279-84.

15. Darke S, Ross J, Teesson M (2007) The Australian Treatment Outcome Study (ATOS). what have we learnt about treatment for heroin dependence? Drug Alcohol Rev 26: 49-54.

16. Harrell PT, Mancha BE, Petras H, Trenz RC, Latimer WW (2012) Latent classes of heroin and cocaine users predict unique HIV/HCV risk factors. Drug Alcohol Depend 122: 220-227.

17. Malcolm BP, Hesselbrock MN, Segal B (2006) Multiple substance dependence and course of alcoholism among Alaska native men and women.Subst Use Misuse 41: 729-741.
18. Patterson TL, Semple SJ, Zians JK, Strathdee SA (2005). Methamphetamineusing HIV-positive men who have sex with men: correlates of polydrug use. $J$ Urban Health 82: i120-i126.

19. Semple SJ, Strathdee SA, Zians J, Patterson TL (2009) Sexual risk behavio associated with co-administration of methamphetamine and other drugs in sample of HIV-positive men who have sex with men. Am J Addict 18: 65-72.

20. Mimiaga MJ, Reisner SL, Vanderwarker R, Gaucher MJ, O'Connor CA, et al. (2008) Polysubstance use and HIVISTD risk behavior among Massachusetts men who have sex with men accessing Department of Public Health mobile van services: Implications for intervention development. AIDS Patient Care STDS 22: 745-751.

21. Kuramoto SJ, Bohnert AS, Latkin CA (2011) Understanding subtypes of innercity drug users with a latent class approach. Drug Alcohol Depend 118: 237 243

22. Patra J, Fischer B, Maksimowska S, Rehm J (2009) Profiling poly-substance use typologies in a multi-site cohort of illicit opioid and other drug users in Canada-a latent class analysis. Addict Res Theory 17: 168-185.

23. Jones HE, Browne FA, Myers BJ, Carney T, Ellerson RM, et al. (2011) Pregnant and non pregnant women in cape town, South Africa: drug use, sexual behavior, and the need for comprehensive services. Int J Pediatr 2011: 353410.

24. Wechsberg WM, Luseno WK, Karg RS, Young S, Rodman N, et al. (2008) Alcohol, cannabis, and methamphetamine use and other risk behaviours among Black and Coloured South African women: a small randomised trial in the Western Cape. Int J Drug Policy 19: 130-139.

25. Wechsberg WM (1998) Revised Risk Behavior Assessment, Part I and Part II. Research Triangle Institute, Research Triangle Park, NC.

26. Muthen LK, Muthen BO (2006) Mplus User's Guide. (6th edn) Muthen \& Muthen, Los Angeles.

27. Myers B, Louw J, Pasche S (2011) Gender differences in barriers to alcohol and other drug treatment in Cape Town, South Africa. Afr J Psychiatry (Johannesbg) 14: 146-153.

28. Browne FA, Wechsberg WM (2010) The intersecting risks of substance use and HIV risk among substance-using South African men and women. Curr Opin Psychiatry 23: 205-209.

29. Tenkorang EY, Maticka-Tyndale E, Rajulton $F$ (2011) A multi-level analysis of risk perception, poverty and sexual risk-taking among young people in Cape Town, South Africa. Health Place 17:525-535.

30. Sawyer KM, Wechsberg WM, Myers BJ (2006) Cultural similarities and differences between a sample of Black/African and colored women in South Africa: convergence of risk related to substance use, sexual behavior, and violence. Women Health 43: 73-92. 